\title{
Radial nerve palsy in the newborn: a case series
}

\author{
Fatema S. Alsubhi MD, Abdullah M. Althunyan MD ABS, Christine G. Curtis BScPT MSc, \\ Howard M. Clarke MD PhD
}

See related commentary by Lundy on page 1348 and at www.cmaj.ca/lookup/doi/10.1503/cmaj.110972.

\section{Abstract \\ Background: Peripheral nerve palsies of the upper extremities presenting at birth can be distressing for families and care providers. It is therefore important to be able to identify pa- tients whose diagnosis is compatible with full recovery so that their families can be reassured.}

Methods: We conducted a retrospective review of all infants presenting with weakness of the upper extremity to our clinic between July 1995 and September 2009. We also conducted a review of the current literature.

Results: During the study period, 953 infants presented to our clinic. Of these patients, 25 were identified as having isolated radial nerve palsy (i.e., a radial nerve palsy in isolation with good shoulder function and intact flexion of the elbow). Seventeen infants $(68.0 \%)$ had a subcutaneous nodule representing fat necrosis in the inferior posterolateral portion of the affected arm. Full recovery occurred in all patients within a range of one week to six months, and $72.0 \%$ of the patients $(18 / 25)$ had fully recovered by the time they were two months old.

Interpretation: Although the outcome of obstetrical brachial plexus palsy is highly variable, isolated radial nerve palsy in the newborn carries a uniformly favourable prognosis.
$\mathrm{P}$ eripheral nerve palsies in the newborn are uncommon and usually involve the brachial plexus or facial nerve. ${ }^{1}$ Isolated radial nerve palsy in the newborn is a rare phenomenon and may be misdiagnosed as obstetrical brachial plexus palsy. It is important to differentiate between these two conditions, as the management and prognosis of each diagnosis are different. Over the last three decades, multiple reports of small numbers of patients with radial nerve palsy present at birth have been published..$^{2-6}$ This paper presents the largest single series of this lesion currently documented in the literature.

\section{Methods}

We conducted a retrospective review of all patients who had presented to our obstetrical brachial plexus clinic with weakness of the upper extremity from July 1995 to September 2009. When newborns were identified as having isolated radial nerve palsy, we documented their age at the time of presentation, their sex, the side of the involvement (i.e., the affected arm), the maternal and obstetrical histories, clinical features, management of the condition and the outcome. For two patients, final follow-up was possible only by telephone interview. The Research Ethics Board at the Hospital for Sick Children approved this study.

\section{Results}

During the study period, 953 infants less than one year of age were seen at our clinic. Twenty-five infants $(2.6 \%)$ were identified as having an isolated radial nerve palsy, and their demographic data are summarized in Table 1. Fifty-six infants (5.9\%) presented with pseudoparalysis, in which a fracture of the ipsilateral clavicle or humerus causes limited movement because of pain.

Of the 25 infants with isolated radial nerve palsy, 13 had been delivered by cesarean section either because of a failure of labour to progress or because of cephalopelvic disproportion. Seven infants were delivered vaginally with the assistance of forceps, and vacuum extraction was used to assist with two deliveries. Two infants were delivered vaginally after a prolonged labour but without instrumentation. One infant was delivered vaginally with no apparent complications during labour and delivery.

Seventeen infants presented with complete inability to extend the wrist (i.e., wrist drop) and inability to extend the thumb and the metacarpophalangeal joints of the fingers (Figure 1A),
Competing interests: None declared.

This article has been peer reviewed.

Correspondence to:

Dr. Howard Clarke,

howard.clarke@utoronto.ca

CMAJ 2011. DOI:10.1503

/cmaj.110272 
although movement of the shoulder and elbow, pronation and supination of the forearm and flexion of the wrist and digits were normal (Figures $1 \mathrm{~B}$ and $1 \mathrm{C}$ ). Physical examinations of the remaining eight patients were normal at the time of presentation, but the histories as given by the families and documented by the referring physicians were of a wrist drop and not generalized brachial plexus palsy.

Seventeen patients $(68.0 \%)$ had a firm subcutaneous nodule (usually about $1 \mathrm{~cm}$ in diameter) in the affected extremity. Clinically, this nodule was thought to be an area of fat necrosis. Seven of these 17 patients had bruising in the posterolateral aspect of the inferior arm (Figure 2). Physiotherapy (passive range-of-motion exercises) and a static splint were provided, as necessary, for a limited period of time. Full recovery for all patients was confirmed during a follow-up visit or by telephone, at an age that ranged from one week to six months, and $72 \%$ of the patients had recovered fully by the time they were two months old.

\section{Interpretation}

Previously, to our knowledge, 35 cases of isolated radial nerve palsy in the newborn have been reported in the literature. ${ }^{2-8}$ This case series reports on an additional 25 patients with isolated radial nerve palsy in the newborn. The characteristic clinical features of a prolonged labour and the presence of a firm subcutaneous nodule along the course of radial nerve in the arm were commonly seen. Furthermore, the spontaneous recovery we saw among our patients had been previously described in the literature.

The pathophysiology of isolated radial nerve palsy in the newborn is thought to be secondary to prolonged pressure on the inferior arm applied by the pelvic brim either in utero or during delivery.

\begin{tabular}{|c|c|c|c|c|c|c|c|c|}
\hline $\begin{array}{l}\text { Patient } \\
\text { no. }\end{array}$ & $\begin{array}{c}\text { Age at } \\
\text { presentation, } \\
\text { w }\end{array}$ & Sex & $\begin{array}{c}\text { Maternal } \\
\text { history of } \\
\text { gestational } \\
\text { diabetes }\end{array}$ & $\begin{array}{l}\text { Mode } \\
\text { of delivery }\end{array}$ & $\begin{array}{l}\text { Birth } \\
\text { weight, } \\
\text { kg }\end{array}$ & $\begin{array}{l}\text { Affected } \\
\text { arm }\end{array}$ & $\begin{array}{c}\text { Subcutaneous } \\
\text { nodule* }\end{array}$ & $\begin{array}{c}\text { Age at } \\
\text { documented } \\
\text { full recovery }\end{array}$ \\
\hline 1 & 1 & Female & No & Cesarean section & 3.4 & Left & Yes & $6 w$ \\
\hline 2 & 1 & Male & No & Cesarean section & 3.3 & Right & No & $5 w$ \\
\hline 3 & 1 & Female & Yes & Vaginal & 4.4 & Left & Yes & 3 mot \\
\hline 4 & 1 & Female & No & Vaginal & 3.7 & Right & Yes & $1 \mathrm{w}$ \\
\hline 5 & 3 & Female & Yes & Cesarean section & 3.7 & Right & Yes & $3 w$ \\
\hline 6 & 6 & Male & No & Vaginal & 3.2 & Right & No & $6 w$ \\
\hline 7 & 3 & Male & No & Cesarean section & 3.1 & Right & No & $6 \mathrm{mo}$ \\
\hline 8 & 1 & Male & Yes & Vaginal & 3.9 & Left & Yes & $3 \mathrm{mo}$ \\
\hline 9 & 1 & Female & No & Cesarean section & 3.7 & Left & Yes & $6 w$ \\
\hline 10 & 4 & Male & No & Cesarean section & 4.0 & Left & No & $4 w$ \\
\hline 11 & 3 & Male & No & Vaginal & 3.8 & Left & Yes & $3 \mathrm{mo}$ \\
\hline 12 & 3 & Male & No & Cesarean section & 3.7 & Right & Yes & $3 w$ \\
\hline 13 & 4 & Female & No & Vaginal & 3.8 & Left & Yes & $4 w$ \\
\hline 14 & 6 & Male & No & Cesarean section & 4.1 & Right & Yes & $6 w$ \\
\hline 15 & 3 & Female & No & Cesarean section & 4.0 & Right & Yes & $2 \mathrm{mo}$ \\
\hline 16 & 4 & Male & No & Cesarean section & 3.0 & Right & Yes & $6 w$ \\
\hline 17 & 2 & Female & No & Cesarean section & 3.9 & Left & No & $3 \mathrm{mo}$ \\
\hline 18 & 2 & Male & No & Cesarean section & 3.9 & Left & No & $2 w$ \\
\hline 19 & 2 & Female & No & Vaginal & 3.8 & Right & Yes & $2 \mathrm{mo}$ \\
\hline 20 & 1 & Male & No & Vaginal & 3.7 & Left & Yes & $2 \mathrm{mo}$ \\
\hline 21 & 4 & Male & No & Cesarean section & 3.0 & Left & No & $3 \mathrm{mo}$ \\
\hline 22 & 8 & Male & No & Vaginal & 3.7 & Left & Yes & $2 \mathrm{mo}$ \\
\hline 23 & 2 & Male & Yes & Vaginal & 2.9 & Left & Yes & $2 \mathrm{mo}$ \\
\hline 24 & 2 & Male & No & Vaginal & 3.7 & Right & Yes & 2 mot \\
\hline 25 & 7 & Male & No & Vaginal & 3.5 & Left & No & $3 \mathrm{mo}$ \\
\hline
\end{tabular}


The evidence for in utero compression includes active denervation of the muscle (as evidenced by fibrillation on electromyography) within the first week after birth. ${ }^{4}$ Normally, such denervation would be expected to appear a minimum of 10 days after injury to the nerve. Hyman and colleagues believe that the lesion occurs during the birth process. ${ }^{2}$ Coppotelli noted a clear pressure mark on the arm of one newborn, and a biopsy from the area showed inflammatory changes and traumatic fat necrosis, 9 suggesting a more longstanding process. There is no consensus as to whether the lesion occurs during late pregnancy, during delivery or both.

Isolated radial nerve palsy must be differentiated from other causes of wrist drop in the newborn. The diagnosis of radial nerve palsy in the newborn depends on its identification in isolation with good shoulder function and intact flexion of the elbow. In obstetrical brachial plexus palsy, wrist drop is usually associated with paralysis of the shoulder, reduced flexion of the elbow and reduced external rotation of the upper extremity. In contrast, external rotation of the shoulder was universally present at birth among the patients we saw with isolated radial nerve palsy, and a subcutaneous nodule representing fat necrosis was seen in the inferior posterolateral aspect of the arm in $68.0 \%$ of our patients.

Our clinic does not conduct electrophysiologic studies in newborn patients with weakness of the upper limb. The results of electromyo- graphic and nerve conduction studies in obstetrical brachial palsy have been shown to suggest a falsely optimistic prognosis. ${ }^{10}$ Given that all of the patients we have seen with isolated radial nerve palsy have had complete spontaneous recovery, the addition of a test that causes discomfort to the patient was not deemed to be appropriate.

Another cause of radial nerve palsy may be a fracture of the humerus as a result of a traumatic delivery. ${ }^{3}$ When this occurs, however, clinical and radiologic evidence of the fracture is usually identified.

Rarely, neonatal wrist drop may be caused by infantile cortical hyperostosis (Caffey disease) involving the lower humerus. This condition is characterized by a sudden onset of soft tissue swelling in the lower arm, fever and irritability. Subsequent radiographic evidence will show periosteal formation of new bone in the lower humerus. Caffey disease is usually self-limiting, and spontaneous recovery of the radial nerve almost always occurs. ${ }^{11}$

Radial nerve palsy affecting premature infants after long-term application of an arm cuff for the measurement of blood pressure has also been reported. ${ }^{8}$ Placing the blood pressure cuff more superiorly on the arm, away from the elbow joint to avoid the most superficial portion of the radial nerve, may prevent this type of compression injury. ${ }^{8}$

Four newborns with high radial nerve palsy

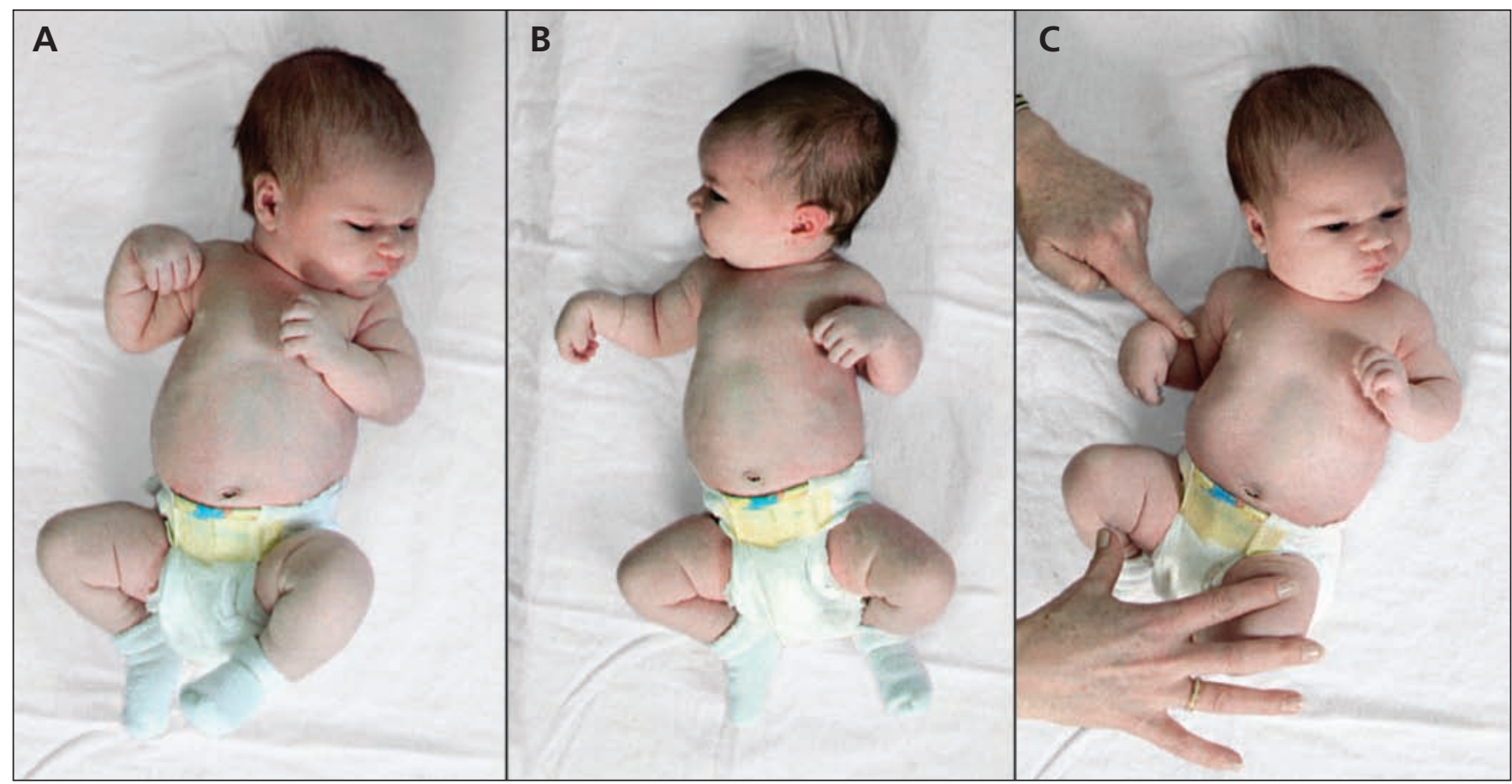

Figure 1: Typical posture of the upper limb in right radial nerve palsy of the newborn. The patient shows a wrist drop and an inability to extend the thumb and metacarpophalangeal joints of the fingers (A), active external rotation of the right shoulder, which is universally seen in radial nerve palsy of the newborn (B), and intact flexion of the right elbow (C). 


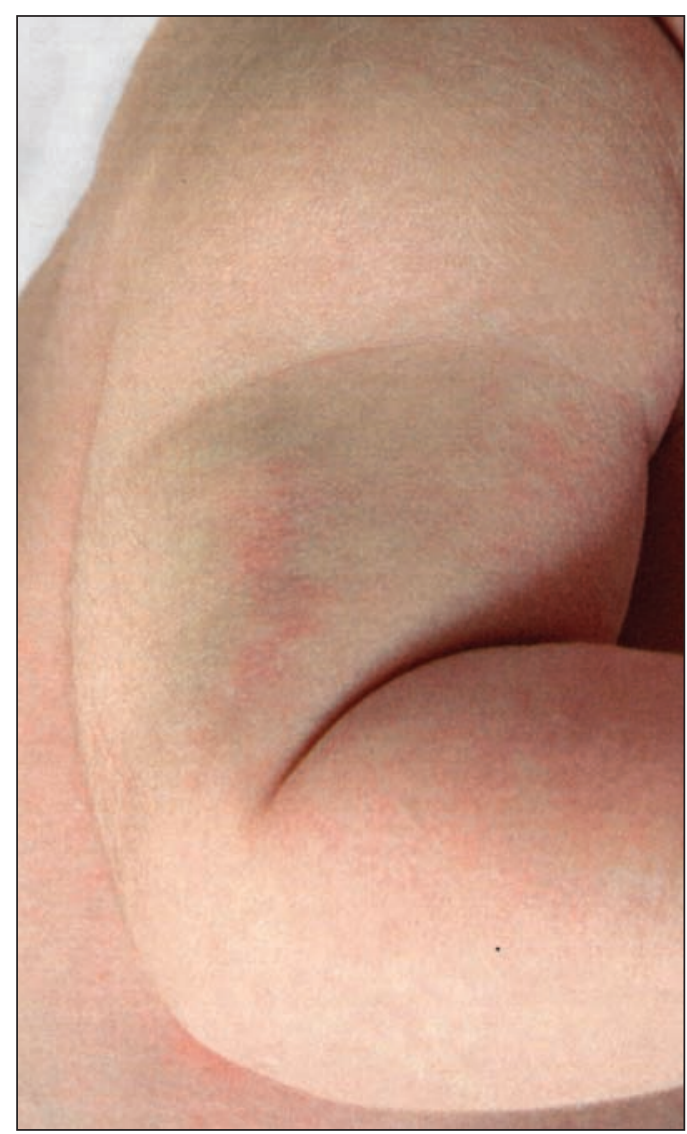

Figure 2: Bruising along the right posterolateral aspect of the arm in a newborn with radial nerve palsy.

associated with septic shoulder were reported by Lejman and colleagues. ${ }^{7}$ Using a cadaveric dissection, they showed that the radial nerve passed close to the shoulder joint and that the capsule, when distended, impinged on the nerve. All four patients fully recovered two to five weeks after their septic shoulders were treated.

Gaur and Swarup reported 56 cases of radial nerve palsy caused by intramuscular injection in the arm, although the youngest patient in their series was one year old. ${ }^{12}$

Most infants with apparent weakness in the upper extremity at birth have sustained an obstetrical brachial plexus lesion. Other causes of limited movement seen at birth include pseudoparalysis $(5.9 \%$ of the infants presenting to our clinic) or isolated radial nerve palsy. Extremely rare causes of a weak upper extremity at birth include tumours and lesions of the spinal cord. Cerebral palsy does not usually present with weakness apparent at birth.

\section{Limitations}

Some selection bias must exist in the collection of our case series. Although we did not discourage referrals to our clinic for even the most mild instances of weakness of the upper extremity, it is unlikely that we saw all of the affected patients from our catchment area.

\section{Conclusion}

Isolated radial nerve palsy as a consequence of delivery is a rare event, but it nearly always proceeds to full and rapid recovery - a more favourable prognosis than that of obstetrical brachial plexus palsy. The diagnosis of isolated radial nerve palsy is thus encouraging news for a family, as the condition does not require surgery or extended treatment.

\section{References}

1. Craig WS, Clark JM. Of peripheral nerve palsies in the newly born. J Obstet Gynaecol Br Emp 1958;65:229-37.

2. Hayman M, Ronald EH, Hill A. Newborn radial nerve palsy: report of four cases and review of published reports. Pediatr Neurol 1999;21:648-51.

3. Morgan L. Radial nerve paralysis in the newborn. Arch Dis Child 1948;23:137-9.

4. Ross D, Jones R, Fisher J, et al. Isolated radial nerve lesion in the newborn. Neurology 1983;33:1354-6.

5. Deshmukh NV, Phillips GE. Isolated radial nerve palsy in newborn, report of two cases. Hand Surg 2002;7:293-4.

6. Monica JT, Waters PM, Bae DS. Radial nerve palsy in the newborn: a report of four cases and literature review. $J$ Pediatr Orthop 2008;28:460-2.

7. Lejman T, Strong M, Michno P. Radial-nerve palsy associated with septic shoulder in neonates. J Pediatr Orthop 1995;15:169-71.

8. Töllner U, Bechinger D, Pohlandt F. Radial nerve palsy in a premature infant following long-term measurement of blood pressure. J Pediatr 1980;96:921-2.

9. Coppotelli BA, Lonsdale JD, Kass E. Sclerema neonatorum complicated by radial nerve palsy following nontraumatic delivery. Mt Sinai J Med 1979;46:143-4.

10. Vredeveld JW, Blaauw G, Slooff BACJ, et al. The findings in paediatric obstetric brachial palsy differ from those in older patients: A suggested explanation. Dev Med Child Neurol 2000; 42:158-61.

11. Finsterbush A, Husseini N. Infantile cortical hyperostosis with unusual clinical manifestations. Clin Orthop Relat Res 1979; (144):276-9.

12. Gaur SC, Swarup A. Radial nerve palsy caused by injections. $J$ Hand Surg Br 1996;21:338-40.

Affiliations: From the Division of Plastic Surgery and the Department of Rehabilitation Services, Hospital for Sick Children and the Department of Surgery, University of Toronto, Toronto, Ont.

Contributors: Howard Clarke had full access to all data in the study and guarantees the integrity of the data and accuracy of the analyses. Fatma Alsubhi and Abdullah Althunyan drafted the manuscript. Christine Curtis revised the manuscript critically for important intellectual content. All of the authors have contributed substantially to the design, acquisition of data, analysis and interpretation. All of the authors approved the final version submitted for publication.

Funding: No funding was required in the preparation of this study. 